\title{
Correlation of Oxidative Stress to Severity of Acute Organophosphorus Poisoning
}

\author{
Somia Bashir ${ }^{\mathrm{a}}$, Firdous Khan ${ }^{\mathrm{b}}$, Maria Bashir ${ }^{\mathrm{c}}$ \\ ${ }^{a}$ Demonstrator, Department of Forensic Medicine and Toxicology, SKIMS Medical College, Bemina J\&K \\ ${ }^{\mathrm{b}}$ Lecturer, Department of Forensic Medicine and Toxicology, Govt Medical College, Srinagar, J\&K \\ ${ }^{c}$ Post Graduate Doctor, Department of Physiology, Govt Medical College, Srinagar, J\&K
}

Corresponding Author: Somia Bashir

\begin{abstract}
Organophosphorus compounds may induce oxidative stress leading to generation of free radicals and alterations in antioxidant and scavengers of oxygen free radicals. The present study included one hundred and sixteen patients who had organophosphorus (OP) poisoning of 3-5 hours duration from the time of consuming the poison. The study focused to elucidate the role of free radicals in organophosphorus toxicity by estimation of various oxidative stress markers. The results of the study suggest significant alteration of these oxidative stress markers which in turn suggests significant free radical generation due to $\mathrm{OP}$ poisoning. This may be due to overuse failure of the antioxidant defence system secondary to excessive reactive oxygen species production.

The study also indicated that the incidence of poisoning was more common among males. Overall, the study found that accidental poisoning was far less than suicidal cases with homicidal cases being the rarest. Most of the patients belonged to rural areas.
\end{abstract}

Key Words: organophosphorus, oxidative stress.

\section{INTRODUCTION}

The history of organophosphorus compounds (OP) and their poisonous effect stretches throughout more than a century. Organophosphates and carbamates are used worldwide in pest control. Pesticides are essential for the farmers to ensure a good crop yield. As a result they are available with ease and at a cheap rate everywhere. Most places don't have any restrictions in their supply. As a result they have also become the most commonly used suicidal poisons. They are extremely toxic substances with a very high mortality and morbidity. WHO estimates that about 3 million people are exposed to pesticide poisoning every year and causes about $3,00,000$ deaths per year. India has the highest incidence of patients with organ phosphorus poisoning in the world (1). Information regarding poisoning cases in our region is rather limited. Despite an increased incidence of organophosphorus insecticide poisoning, the exact micro molecular changes that take place remain elusive. Our study was directed towards understanding the toxic effects of organophosphorus poisoning on free radical generation and the antioxidant system of the body. In addition demographic factors of poisoning were also analysed.

\section{MATERIAL AND METHOD}

The study was conducted at Sher-eKashmir institute of Medical sciences Bemina Srinagar which is a tertiary care institute between Sept 2019 to March 2020. Informed consent was obtained from the patients or in some cases was the patient was unable to give consent due to their medical condition, consent was taken from the next of kin. One hundred and sixteen OP poisoned patients (of 3-5 h duration from the time of consuming the poison) were admitted during the said period. The cases included in this study were those who had 
consumed the poison orally or had been exposed to it through accidental inhalation during spraying.

The mean age of the patients was 30 \pm 5 years. The grouping of the OP poisoning cases was done depending upon signs and symptoms.

Grade I - OP poisoned with no signs and symptoms

Grade II - Diarrhea, vomiting, abdominal pain, giddiness

Grade III - Pupillary constriction with above symptoms

Grade IV - Pulmonary edema

Grade V - Unconsciousness

Immediately after admission to the hospital, before starting the appropriate treatment. $10 \mathrm{ml}$ venous blood samples were collected from the subjects under aseptic conditions.

\section{Assay systems}

\section{Protein determination}

Protein was determined by the Comassie blue method using bovine serum albumin as standard. Absorbance of samples was measured at $595 \mathrm{~nm}$ by method Bradford, 1976. ${ }^{(2)}$

\subsection{Acetylcholinesterase activity}

AChE activity was assayed by the method of Ellman etal. $1961^{(3)}$. According to this method, acetylthiocholine (AcSCH) is hydrolyzed by $\mathrm{AChE}$ to acetic acid and thiocholine. The catalytic activity is measured by the increase of the yellow anion, 5-thio-2-nitrobenzoate, produced from thiocholine when it reacts with 5,50dithio-bis-2- nitrobenzoic acid (DTNB). AChE activity was expressed in $\mu$ mol of AcSCH hydrolyzed/ min/ mg protein.

\subsection{Lipid peroxidation}

Serum malondialdehyde, a product of lipid peroxidation, was measured by a thiobarbituric reaction described by Kei Sathoh ${ }^{(4)}$. Serum proteins were precipitated by trichloro acetic acid (TCA) and the mixture was heated for 30 minutes with thiobarbituric acid in $2 \mathrm{M}$ sodium sulphate, in a boiling water bath. The resulting chromogen was extracted with n-butyl alcohol and the absorbance of the organic phase was determined at a wavelength of $530 \mathrm{~nm}$. The values were expressed in terms of $\mathrm{nmol} / \mathrm{ml}$ of malondialdehyde (MDA) using $1,1,3,3$, tetra ethoxy propane as the standard.

\subsection{Superoxide dismutase}

Activity of erythrocyte superoxide dismutase (SOD) was measured by the method of Marklund and Marklund (5). Superoxide anion is involved in the auto oxidation of pyrogallol at alkaline $\mathrm{pH}$ 8.5. The superoxide dismutase inhibits the autooxidation of pyrogallol, which can be determined as an increase in absorbance per two minutes at $420 \mathrm{~nm}$. The SOD activity was measured as Units/gms of $\mathrm{Hb}$. One unit of superoxide dismutase is defined as the amount of enzyme required to cause $50 \%$ inhibition of pyrogallol auto oxidation.

\subsection{Catalase}

Catalase was measured by the method of Aebi $1983^{(6)}$. Heparinized blood was centrifuged and the plasma was removed. The erythrocytes were washed three times with $5 \mathrm{ml} 0.9 \%$ sodium chloride and lysed in 10 volumes of cold deionised water. The whole mixture was centrifuged further for $10 \mathrm{~min}$ at $3,000 \mathrm{rpm}$. The cell debris was removed and the clear hemolysate was diluted 500 times phosphate buffer (60mM, pH- 7.4). Catalase decomposes hydrogen peroxide $\left(\mathrm{H}_{2} \mathrm{O}_{2}\right)$ to form water and molecular oxygen. In the ultra violet range, $\mathrm{H} \mathrm{O}$ shows a continual increase in absorbance with decreasing wavelength. At 240nm, $\mathrm{H}_{2} \mathrm{O}_{2}$ absorbs maximum light. When $\mathrm{H}_{2} \mathrm{O}_{2}$ is decomposed by catalase then the absorbance decreases. The decreased absorbance was measured at $240 \mathrm{~nm}$ at 15 second intervals up to $1 \mathrm{~min}$ and the difference in absorbance $(\Delta \mathrm{A}$ at $240 \mathrm{~nm})$ per unit time was measured. The unit of catalase activity was expressed as $\mathrm{mM}$ of $\mathrm{H}_{2} \mathrm{O}_{2}$ decomposed/mg Hb/min. 


\section{RESULTS}

Table 1 shows the incidence of poisoning in males and females. Out of the total 106 patients 80 were males and 36 were females. This shows that males constituted $68.96 \%$ while as female constituted $31.03 \%$ of the total cases.

\begin{tabular}{|c|c|c|}
\hline \multicolumn{3}{|c|}{ Table 1 Sex } \\
\hline Sex & No of cases & Percentage(\%) \\
\hline Males & 80 & 68.96 \\
\hline Females & 36 & 31.03 \\
\hline
\end{tabular}

The distribution of the cases with respect to the cause of poisoning is shown in table 2. Out of total of 116 cases, 105 were found to be suicidal, 6 cases were found to be accidental and 5 were found to be homicidal. This constituted 91.21, 6.97, 5.8 percentage respectively.

Table 2 Nature of poisoning cases

\begin{tabular}{|l|l|l|}
\hline Nature of poisoning & No. Of cases & Percentage \\
\hline Suicidal & 105 & 91.21 \\
\hline Accidental & 6 & 6.97 \\
\hline Homicidal & 5 & 5.8 \\
\hline
\end{tabular}

As far as the geographic distributions of the patients were concerned, 96 patients were found to be from rural area and 20 patients were from urban area. Thus $83.01 \%$ were rural residents and $17.24 \%$ were urban residents.

Table 3. Geographic distribution

\begin{tabular}{|l|l|l|}
\hline Distribution & No.of cases & percentage \\
\hline Rural & 96 & 83.01 \\
\hline Urban & 20 & 17.24 \\
\hline
\end{tabular}

Table 4 shows AChE activity (mean \pm SD) in erythrocytes in the control and various patient groups

Table 4

\begin{tabular}{|l|l|}
\hline Group & $\boldsymbol{\mu}$ Tabol of AcSCH hydrolyzed/ min/ mg protein \\
\hline Control & $1.29 \pm 0.13$ \\
\hline Grade 1 & $0.91 \pm 0.03^{*}$ \\
\hline Grade 2 & $0.68 \pm 0.10^{*}$ \\
\hline Grade 3 & $0.54 \pm 0.04^{*}$ \\
\hline Grade 4 & $0.44 \pm 0.01^{*}$ \\
\hline Grade 5 & $0.38 \pm 0.02^{*}$ \\
\hline
\end{tabular}

Table 5

\begin{tabular}{|l|l|}
\hline Group & Serum MDA $(\mathbf{n m o l} / \mathbf{m l})$ \\
\hline Control & $4.23 \pm 0.008$ \\
\hline Grade 1 & $4.53 \pm 0.00$ \\
\hline Grade 2 & $4.89 \pm 0.016$ \\
\hline Grade 3 & $5.87 \pm 0.273^{*}$ \\
\hline Grade 4 & $5.97 \pm 0.20^{*}$ \\
\hline Grade 5 & $6.01 \pm 0.12^{*}$ \\
\hline
\end{tabular}

Table 5 shows organophosphorus poisoning induced lipid peroxidation.

Table 6 shows superoxide dismutase and catase activity (Mean \pm S.D) in control and various groups

\begin{tabular}{|l|l|l|}
\hline \multicolumn{2}{|c}{ Table 6 } \\
\hline Groups & $\begin{array}{l}\text { Superoxide } \\
\text { dismutase } \\
(\mathbf{U} / \text { gmHb) }\end{array}$ & $\begin{array}{l}\text { Catalase }(\mathbf{M m} \text { H2O2 } \\
\text { decomposed/mgHb/min })\end{array}$ \\
\hline Control & $12.54 \pm 0.0007$ & $15.88 \pm 0.198$ \\
\hline Grade 1 & $17.07 \pm 0.139$ & $17.86 \pm 0.123$ \\
\hline Grade 2 & $19.69 \pm 0.008$ & $19.69 \pm 0.008$ \\
\hline Grade 3 & $9.86 \pm 0.126$ & $11.021 \pm 0.007$ \\
\hline Grade 4 & $8.36 \pm 0.24$ & $10.04 \pm 0.01$ \\
\hline Grade 5 & $3.99 \pm 0.113$ & $9.97 \pm 0.62$ \\
\hline
\end{tabular}

\section{DISCUSSION}

On analysing the demographic profile our study found that the incidence of poisoning was more common among males than females. We found most cases belonged to rural areas. This could be attributed to more wide spread use and easy availability of Ops in rural areas. These results are similar to those found by Mitesh D. Falia ${ }^{(7)}$.

The study was primarily focused to elucidate the role of free radicals in organophosphorus toxicity.

These compounds manifest their toxicity by irreversibly inhibiting the enzyme acetylcholinesterase (AChE) at the nerve synapse resulting in excessive accumulation of $\mathrm{ACh}$, leading to the paralysis of cholinergic transmission in the CNS, autonomic ganglia, parasympathetic nerve endings, some sympathetic nerve endings and neuromuscular junction ${ }^{(8)}$. In our study the activity of acetylcholine esterase was significantly inhibited at all grades (Table 2) with maximum inhibition found in the most seriously affected patients. Similar results were obtained by Veerappa et al ${ }^{(9)}$. Inhibition of AChE appears to be the principal mode of action of organophosphorus compounds ${ }^{(10)}$.

It is reported that besides their inhibitory effect on AChE, they also induce changes characteristic of oxidative stress (11)

Superoxide dismutase (SOD is a free radical (superoxide anion; $\mathrm{O}_{2}^{-}$) scavenger. In 
the present study, the activity of superoxide dismutase was increased at grade 1 and 2 as compared to control. The increased activity of SOD reflects an activation of the compensatory mechanism through the effects of pesticides on progenitor cells, and its extent depends on the magnitude of the oxidative stress and hence, on the dose of stressor ${ }^{(12)}$. Superoxide dismutase activity was recorded to be decreased at grade 3,4 $\& 5$. The efforts of the endogenous antioxidant enzymes to remove the continuously generated free radicals initially increase due to their induction but later enzyme depletion results ${ }^{(13)}$.

Further, Superoxide Dismutase catalyzes dismutation reactions resulting in the generation of hydrogen peroxide $\left(\mathrm{H}_{2} \mathrm{O}_{2}\right)$ from free radicals. This $\mathrm{H}_{2} \mathrm{O}_{2}$ is decomposed to water and molecular oxygen by the action of enzyme In the present study, the activity of Catalase was found to show trends similar to those of SOD. Its activity as compared to the controls, was increased at grade 1 and 2 while it was reduced at grade $3,4 \& 5$.

The elevated activity of SOD \& catalase found in our study is thus suggested to be due to adaptive response to the generated free radicals ${ }^{(14)}$.

When the free radical production overwhelms the endogenous antioxidant levels, all the major biomolecules like lipids, proteins, and nucleic acids may be attacked by free radicals, but lipids are probably the most susceptible. ${ }^{(15)}$ The oxidative destruction of lipids (lipid peroxidation) is a destructive, selfperpetuating chain reaction, releasing malonyl aldehyde (MDA) as the end product ${ }^{(13)}$. Our study detected an elevation in MDA indicating enhanced lipid peroxidation. The lipid peroxidation was significantly increased at grade 3, 4 and 5.It is suggested that organophosphorus induced lipid peroxidation at higher grade could possibly result from an enhanced microsomal oxidative capacity induced by OP. Ranjbar et al. reported significant lipid peroxidation accompanied with decreased AChE activity ${ }^{(16)}$.

From our study we conclude that though the effects of Organophosphorus poisoning may be primarily ascribed to the fall in the activity of Acetylcholine esterase activity, there are significant but subtle changes in the cellular Oxidative system resulting in more widespread, as yet, unquantified cellular damage. Further research towards the precise estimation of such cellular destruction and any proposed treatment directed towards such damage may help us to augment the current standard of care treatment resulting in better prognosis of OP poisoning.

\section{Acknowledgement: None}

Conflict of Interest: None

\section{Source of Funding: None}

\section{Ethical Approval: Approved}

\section{REFERENCES}

1. J Vidyasagar, N Karunakar, MS Reddy, K Rajnarayana , T Surender , DR Krishna, Oxidative stress and antioxidant status in acute organophosphorous insecticide poisoning Research paper : 2004, 36, 2, 76-79

2. Bradford MM. A rapid and sensitive method for the quantification of microgram quantities of protein utilizing the principle of protein-dye binding. Anal Biochem 1976, 72, 248-254

3. Ellman GL, Courtney KD, Andres Jr V. A new and rapid colorimetric determination of acetylcholinesterase activity. Biochem. Pharmacol 1961, 7, 88-95.

4. Satho Kei. Serum lipid peroxide in cerebrovascular disorders determined by a new colorimetric method. Clin Chimica Acta. 1978,90,37-43.

5. Anuradha Nandi, I. B. Chatterjee. Assay of superoxide dismutase activity in animal tissues. J Biochem. 1988,13(3),305-315.

6. Aebi H. Catalase in vitro. Methods Enzymol. 1984,105,121-126.

7. Mitesh D. Falia, Prasad Kulkarni, Narsimha Reddy, Somashekaram P. Outcomes of 
patients with self-posioning with organophosphorus pesticides at a rural tertiary care hospital in Southern India. International journal of research in medical sciences.2016, 4,no7.

8. Vishwananthan R, Srinivasan V. Treatment of OP compound poisoning. J Indian Med Assoc 1964,43,494-7.

9. Veerappa Annasaheb Kothiwale, Vivek Veereshkumar Shirol, Viraj V Yerramalla, Vijayakumar G Somannavar Association between serum cholinesterase levels and clinical outcome in patients of organophosphorus compound poisoning One-year hospital-based longitudinal study 2019, vol 7, 4, 109-116

10. Sarkar,S.N.,Hazarika,A., Sunil Hajare,M., Kataria J.K., Malik.Influence of malathion pre-treatment on the toxicity of anilofos in male rats: a biochemical interaction study. Toxicology 2003 185,1-8.

11. Malkovics B. Effect of organophosphates on the antioxidant systems of fish tissue. Acta Biol Hung 1995,9,11.

12. Prakasam,A.,Sethupathy,S., Lalitha, S. Plasma and $\mathrm{RbCs}$ antioxidant status in occupational male pesticide sprayers. Clin. Chim.Acta. 2001,310,107-112.
13. Cheeseman KH. Lipid peroxidation in biological system. In: Halliwell B, Aruoma ok, editors. DNA and Free radicals. London: Ellis Horwood; 1993, 201-11.

14. Koner,B.C.,Banerjee,B.D.,Ray,A.,.Organoc hlorine pesticide induced oxidative stress and immune suppression in rats.Indian J.Exp.Biol. 1998,36, 395-398.

15. Cheeseman KH, Slater JF. An introduction to free radical biochemistry. In: Cheeseman $\mathrm{KH}$, Slater TS, editors. Free radicals in medicine. New York: Churchill Livingstone; 1992, 481-93.

16. Ranjbar A, Solhi H, Mashayekhi FJ, Susanabdi A, Rezaie A, Abdollahi M. Oxidative stress in acute human poisoning with organophosphorus insecticides: a case control study. Env Toxicol Pharmacol. 2005,20,88-91

How to cite this article: Bashir S, Khan F, Bashir M. Correlation of oxidative stress to severity of acute organophosphorus poisoning. International Journal of Research and Review. 2021; 8(5): 138-142. DOI: https://doi.org/ 10.52403/ijrr.20210520 